\title{
Changes in Commute Mode Attributed to COVID-19 Risk in Canadian National Survey Data
}

\author{
M. Anne Harris ${ }^{1}$ (), Michael Branion-Calles ${ }^{2}$ (1) \\ ${ }^{1}$ School of Occupational and Public Health, Ryerson University; Dalla Lana School of Public Health, University of Toronto, ${ }^{2}$ School of Occupational and Public \\ Health, Ryerson University; Department of Emergency Medicine, University of British Columbia \\ Keywords: transit, commute, pandemic, canada, covid-19 \\ 10.32866/001c.19088
}

\section{Findings}

\begin{abstract}
Transportation shifts in Canada precipitated by COVID-19 may persist into recovery. We examined commuters in a national survey (Canadian Perspectives Survey Series 3) and commute changes attributed to COVID-19 risk. We modeled associations of changing commute with pre-COVID-19 mode, adjusting for coarse socio-demographic covariates. We found that all out-of-home commute modes declined during COVID-19, with increases in telework. Commuting by public transit was most strongly associated with change in commute mode to avoid COVID-19 risk. Among pre-COVID-19 transit commuters, $18.2 \%$ continue to rely on transit, and personal motor vehicle use is more common $(13.0 \%)$ than walking $(3.4 \%)$ or cycling $(2.9 \%)$.
\end{abstract}

\section{Questions}

In Canada, the COVID-19 pandemic has altered commuting through teleworking/remote learning, unemployment, reduced transit service, and commuter safety concerns. Previous analyses have examined mobility and traffic data (e.g. Amberber et al. 2021) to document declining transport movement. Declining public transit ridership and revenue has reduced service levels by Canadian transit agencies (Boisvert 2020). Given the potential for COVID-19 circulation across multiple years (Scudellari 2020), it is important to understand individual transport mode choices attributable to avoidance of COVID-19 risk. Using a national survey, this paper explores changes in commute mode due to COVID-19 among Canadians and the effects of coarse sociodemographic variables on this relationship, asking: what is the association between the mode of transport used before COVID-19 and changes in commute mode to avoid COVID-19 risk?

\section{Methods}

We examined data from the Canadian Perspectives Survey Series (CPSS) 3: Resuming Economic and Social Activities During COVID-19 (Statistics Canada 2020a). We used the CPSS3 Public Use Microdata File (PUMF), released in December, 2020. The survey was conducted by Statistics Canada in June, 2020, as part of a multi-wave effort to evaluate the impact of COVID-19 on Canadians. In June of 2020, the first wave of the pandemic had waned in most parts of Canada and many sectors had begun reopening (Canadian Institute for Health Information 2020). The CPSS3 targeted Canadians 15 years and older, excluding residents of Northern Territories. Persons living onreserve, in institutions, and in "extremely remote" areas were also excluded. We followed Statistics Canada guidelines regarding the use of survey weights to 


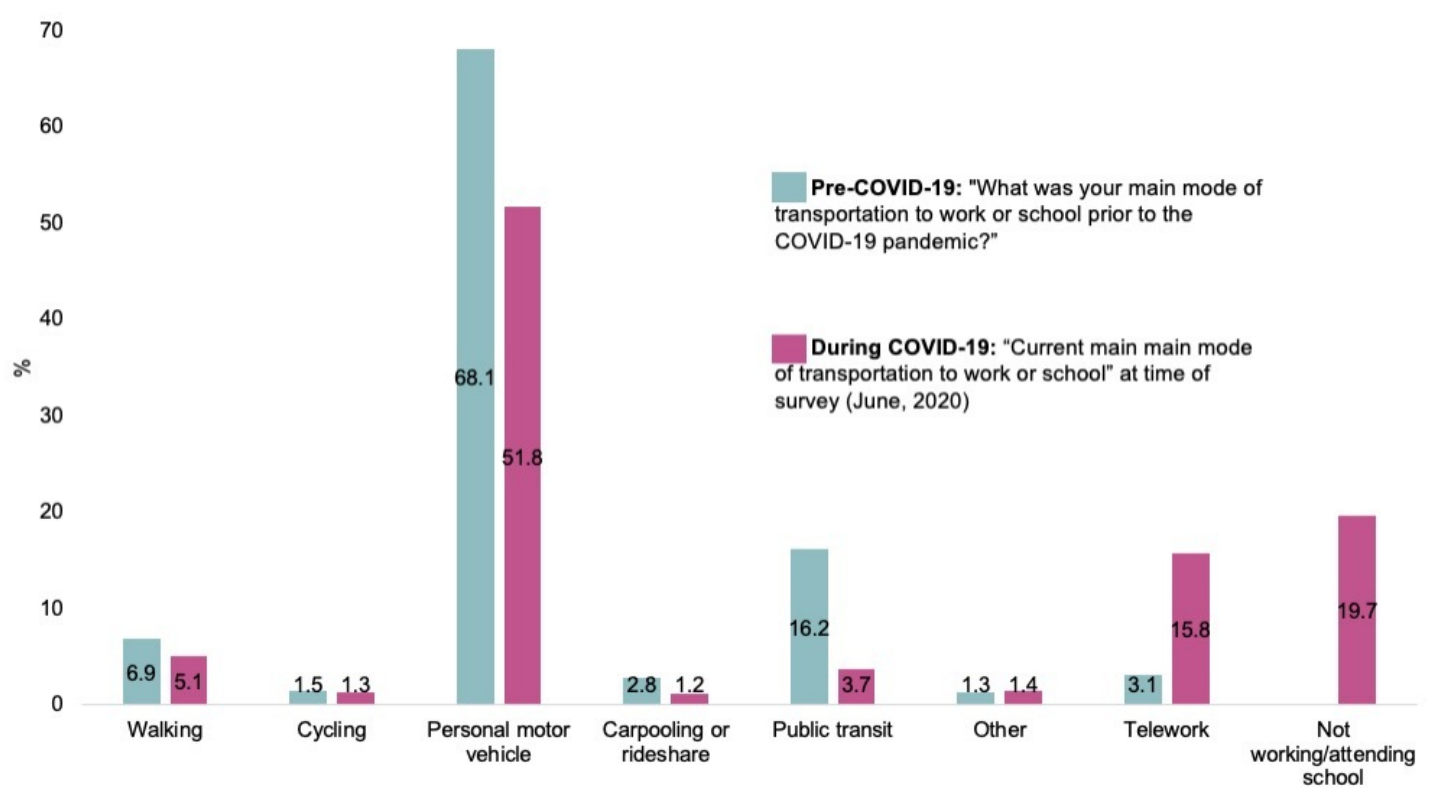

Figure 1. Commute modes before and during COVID-19 among Canadians who reported attending work or school prior to COVID-19 in the Canadian Perspectives Survey Series 3.

construct percentage estimates and minimum raw counts for denominators of proportions (Statistics Canada 2020b). Any unweighted Ns provided below have been rounded to the nearest 100 to comply with guidelines (Statistics Canada 2020b).

Of the 4,200 total participants in the CPSS3, we analyzed a subset ( $\mathrm{n} 2900$, representing 23,069,500 Canadians) who were "pre-COVID-19 commuters": those who indicated a mode of transport in response to "What was your main mode of transportation to work or school prior to the COVID-19 pandemic?" We compared the indicated modes to the "current mode of" to observe changes in mode share.

To examine avoidance of COVID-19 risk, we used a question posed to respondents who indicated a change in their main mode of to work or school: "What are the reasons for the change in your main mode of ?" Participants who selected "COVID-19 risk" in response defined our key outcome $(1=$ if commute changed with "COVID-19 risk" as the reason, 0 otherwise). We conducted logistic regression to model the odds of changing commute due to COVID-19 risk. Our primary explanatory variable was mode of transport to work or school before COVID-19. Relevant covariates available in CPSS3 were age, sex, level of education, immigration history (yes/no), and urban/ rural location. Lastly, we examined percentage of current modes among for preCOVID-19 public transit commuters ( $n \sim 300)$. Analyses were performed using SAS 9.4 (Cary, NC, USA). 
Table 1. Summary data (percentages) for participants in the Canadian Perspectives Survey Series 3 who reported commuting pre-COVID-19. Percentage estimates and standard errors were generated using Statistics Canada survey weights.

\begin{tabular}{|c|c|c|c|c|c|}
\hline & & \multirow{2}{*}{\multicolumn{2}{|c|}{$\begin{array}{l}\text { Overall analytic } \\
\text { sample } \\
\text { N 2900 }\end{array}$}} & \multirow{2}{*}{\multicolumn{2}{|c|}{$\begin{array}{l}\text { Changed commute due to } \\
\text { COVID-19 risk } \\
\text { N } 400\end{array}$}} \\
\hline & & & & & \\
\hline & & $\begin{array}{r}\text { Weighted } \\
\%\end{array}$ & $\begin{array}{l}\mathrm{SE}^{*} \\
(\%)\end{array}$ & Weighted \% & $\mathrm{SE}^{*}(\%)$ \\
\hline \multirow[t]{7}{*}{ Age group } & $15-24$ & 17.7 & 1.3 & 33.0 & 4.1 \\
\hline & $25-34$ & 21.4 & 1.4 & 20.1 & 3.5 \\
\hline & $35-44$ & 20.4 & 1.3 & 18.1 & 3.4 \\
\hline & $45-54$ & 18.3 & 1.3 & 15.3 & 3.1 \\
\hline & $55-64$ & 14.9 & 1.2 & 7.8 & 2.3 \\
\hline & $65-74$ & 5.7 & 0.8 & 4.5 & 1.8 \\
\hline & 75 and older & 1.6 & 0.4 & 1.3 & 1.0 \\
\hline \multirow[t]{2}{*}{ Sex } & Men & 51.7 & 1.7 & 46.0 & 4.4 \\
\hline & Women & 48.3 & 1.7 & 54.0 & 4.4 \\
\hline \multirow[t]{3}{*}{ Education } & High school or less & 36.5 & 1.6 & 42.2 & 4.3 \\
\hline & $\begin{array}{l}\text { College diploma or } \\
\text { trade certificate }\end{array}$ & 10.3 & 1.0 & 2.1 & 1.2 \\
\hline & University & 53.2 & 1.7 & 55.8 & 4.1 \\
\hline \multirow[t]{2}{*}{ Urban/Rural } & Rural & 14.1 & 1.2 & 4.9 & 1.9 \\
\hline & Urban & 85.9 & 1.2 & 95.1 & 1.9 \\
\hline \multirow[t]{2}{*}{ Immigration } & Born in Canada & 75.3 & 1.4 & 67.3 & 4.1 \\
\hline & $\begin{array}{l}\text { Immigrant (landed and } \\
\text { non-landed) }\end{array}$ & 24.7 & 1.4 & 32.7 & 4.1 \\
\hline \multirow{7}{*}{$\begin{array}{l}\text { Commute mode to work or school } \\
\text { before COVID-19 }\end{array}$} & Walking & 6.9 & 0.8 & 3.6 & 1.6 \\
\hline & Cycling & 1.5 & 0.4 & 1.4 & 1.0 \\
\hline & Personal motor vehicle & 68.1 & 1.6 & 38.2 & 4.2 \\
\hline & Carpool or rideshare & 2.8 & 0.6 & 6.3 & 2.1 \\
\hline & Public transit & 16.2 & 1.2 & 49.5 & 4.4 \\
\hline & Other & 1.3 & 0.4 & 0.4 & 0.6 \\
\hline & Telework & 3.1 & 0.6 & 0.5 & 0.6 \\
\hline
\end{tabular}

*Adjustment factor applied based on CPSS PUMF guidelines

\section{Findings}

Among pre-COVID-19 commuters, $17.8 \%\left(\mathrm{SE}_{\text {adjusted }}: 1.3 \%\right)$ changed their commute mode due to COVID-19 risk. Comparing commute modes before and during COVID-19 (Figure 1), declines were observed in all out-of-home modes of transport, with increases in telework and no work/school. 
Most pre-COVID-19 commuters (Table 1) had university-level education, lived in urban settings, and were born in Canada. Most used personal motor vehicles for travel to work and school before COVID-19. Among those who changed their commute due to COVID-19 risk, there were more younger people, women, urban-dwellers and those who used transit before COVID-19.

In our multiple logistic regression (Figure 2), use of public transit and carpooling/rideshare before COVID-19 had the strongest associations with the odds of commute change motivated by COVID-19 risk. Those who teleworked prior to COVID-19 had reduced odds of changing commute mode due to risk, as did those who walked, although the $95 \%$ confidence interval for this estimate included an odds ratio of 1 . Among covariates, those without university education (both high school level and college and trade certificates) had lower odds of a change in commute due to COVID-19 risk, which could be attributable to high proportion of these Canadians in essential jobs that can't be performed by telework. Rural location was also inversely associated with a change in commute due to COVID-19 risk, as compared to urban locations. We note here that the CPSS3 target population excludes many rural parts of Canada (Northern Territories and "very remote" regions), and we emphasize the need for more detailed information on rural regions, which may experience disproportionate pandemic impacts (Savage et al. 2020).

Current commute mode for pre-COVID-19 public transit users is shown in Figure 3 . A plurality of these users reported currently "not attending work or school", a composite category challenging to interpret given the absence of a student status indicator in the CPSS3. Because telework was a distinct category, "not attending work or school" comprises a mix of Canadians who left the work force during the pandemic (unemployed and retired), along with students remote learning or on break from school (if not attending work during this break). Among pre-COVID-19 public transit users still commuting at the time of survey collection, public transit remained the most used mode, but personal motor vehicle reliance was substantial among this population, and exceeded active modes of travel. While this indicates a cause for concern for both traffic management and population health in the post-pandemic recovery, regional data will be important to identifying local patterns in adoption of new travel modes. There is also a crucial need to incorporate relevant data on social determinants that the CPSS3 PUMF lacks, including ethnicity, race, occupation, and income, to ensure equitable management and recovery (McKenzie 2020). 


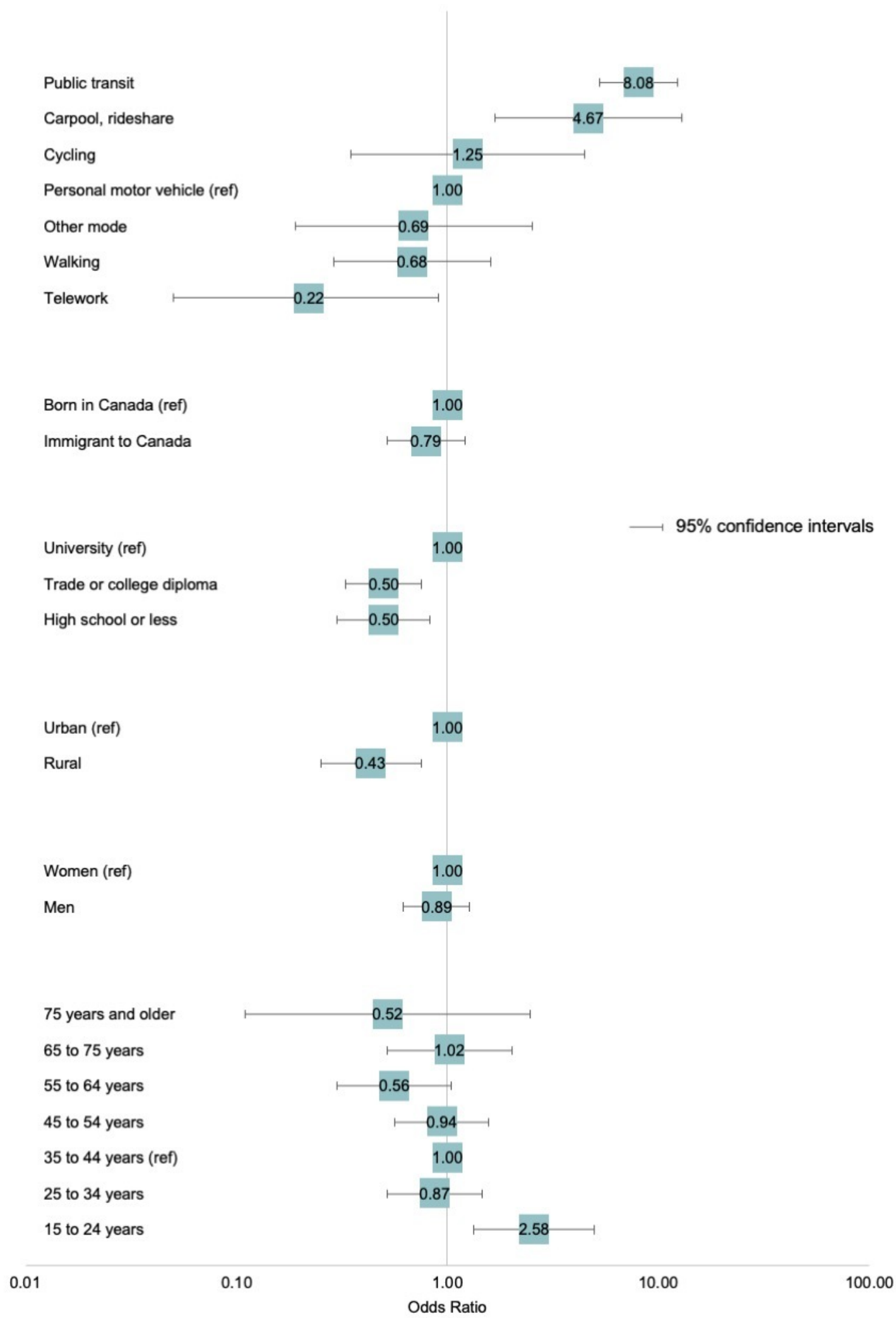

Figure 2. Results of logistic regression modeling odds of change in commute due to COVID-19 risk, and its relationship to pre-COVID-19 commute mode and available covariates. Analyses used the Canadian Perspectives Survey Series 3 Public Use Microdata File. 
How are pre-COVID-19 public transit users commuting during COVID-19?

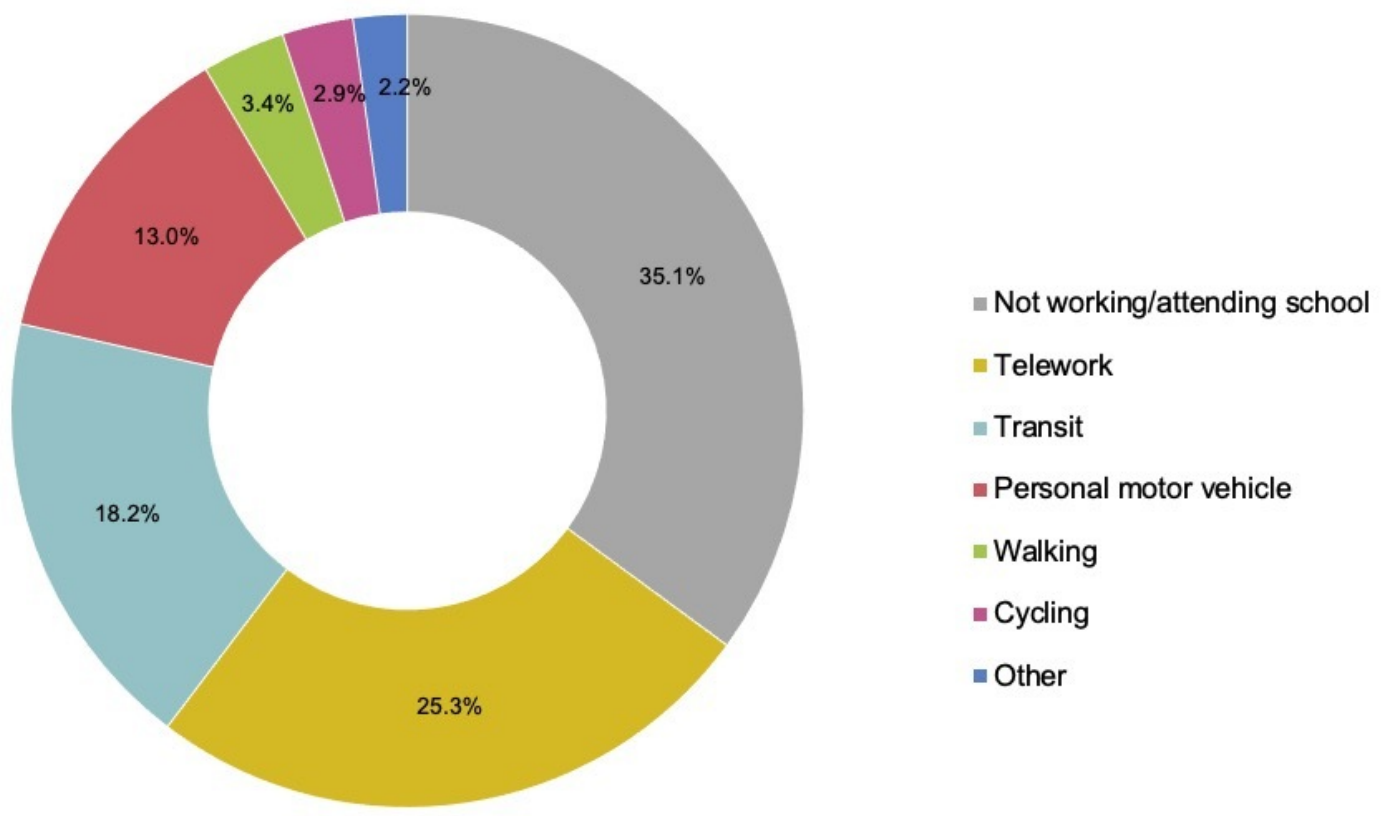

Figure 3. Current mode of commute among pre-COVID-19 public transit commuters in Canada surveyed in June, 2020. Analyses used the Canadian Perspectives Survey Series 3 Public Use Microdata File.

\section{Acknowledgements}

Data for this study were collected by Statistics Canada and public use data access was provided by the Ontario Data Documentation, Extraction Service and Infrastructure (<odesi>), managed by the Ontario Council of University Libraries (OCUL). Salary support for MBC was provided by a Canadian Institutes of Health Research (CIHR) operating grant held by MAH. 


\section{REFERENCES}

Amberber, Nahomi, Andrew Howard, Meghan Winters, M. Anne Harris, Ian Pike, Alison Macpherson, Marie-Soleil Cloutier, et al. 2021. "Road Traffic Injury during the Covid-19 Pandemic: Cured or a Continued Threat?" University of Toronto Journal of Public Health 2 (1): 1-7. https://doi.org/10.33137/utjph.v2i1.34737.

Boisvert, N. 2020. “TTC Facing \$92M Monthly Shortfall, Plummeting Ridership Due to COVID-19," May 14, 2020. cbc.ca. https://www.cbc.ca/news/canada/toronto/ttc-financescovid19-1.5569867.

Canadian Institute for Health Information. 2020. "COVID-19 Intervention Timeline in Canada." Online tool. 2020. https://www.cihi.ca/en/covid-19-intervention-timeline-in-canada.

McKenzie, K. 2020. "Race and Ethnicity Data Collection during COVID-19 in Canada: If You Are Not Counted You Cannot Count on the Pandemic Response." In The Impact of COVID-19 in Racialized Communities. Royal Society of Canada. https://rsc-src.ca/en/race-and-ethnicity-datacollection-during-covid-19-in-canada-if-you-are-not-counted-you-cannot-count.

Savage, David, Andrew Fisher, Salimur Choudhury, Robert Ohle, Roger Strasser, Aaron Orkin, and Vijay Mago. 2020. "Investigating the Implications of COVID-19 for the Rural and Remote Population of Northern Ontario Using a Mathematical Model.” Pre-print via medRxiv. https://doi.org/10.1101/2020.09.17.20196949.

Scudellari, Megan. 2020. "How the Pandemic Might Play out in 2021 and Beyond." Nature (News Feature), August 5, 2020. https://doi.org/10.1038/d41586-020-02278-5.

Statistics Canada. 2020a. "Canadian Perspectives Survey Series 3: Resuming Economic and Social Activities during COVID-19.” https://www150.statcan.gc.ca/n1/daily-quotidien/200708/ dq200708a-eng.htm.

-_-. 2020b. "Canadian Perspective Survey Series 3: Resuming Economic and Social Activities During COVID-19: Study Documentation and Public-Use Microdate File Guide.” Ontario Data Documentation, Extraction Service and Infrastructure. 